\title{
Analgesic efficacy of oral gabapentin added to standard epidural corticosteroids in patients with failed back surgery
}

This article was published in the following Dove Press journal:

Clinical Pharmacology:Advances and Applications

29 September 2010

Number of times this article has been viewed

\author{
Beyazit Zencirci \\ Department of Anesthesiology \\ and Reanimation, Medical Faculty \\ of Sutcu Imam University, \\ Kahramanmaras, Turkey
}

Correspondence: Beyazit Zencirci M. Akif Inan Mah Alparslan Turkes Bulvari, Seyhan Apt No 209 D 5, Merkez, 46050-Kahramanmaras, Turkey

Tel +903442258300

Fax +903442258303

Email bzencirci@fastmail.fm
Objective: Failed back surgery syndrome is characterized by the presence of intractable pain and varying degrees of functional incapacity after lumbar spine surgery. Because the mechanisms that cause pain are variable, treatment of this syndrome is quite difficult, and one of the most common methods that is used for treatment nowadays is epidural injection. This research evaluates the analgesic efficacy of addition of oral gabapentin treatment to epidural corticosteroid application in patients with failed back surgery syndromes.

Methods: Forty-two patients, including 23 females and 19 males, with failed back surgery syndrome who had been previously operated on at least twice due to lumbar disc herniation were randomly divided into two groups. Following epidural application of a single dose of methylprednisolone in the first group of patients (Group K), an oral medical treatment containing naproxen sodium, tizanidine, and vitamin $\mathrm{B}$ and $\mathrm{C}$ complex, was devised to be applied for one month. For the second group, oral gabapentin was added to the same treatment regime (Group G). Pain levels were evaluated by a visual analog scale for straight leg raise before, during, and after treatment, as well as in the first and third months.

Results: There was no demographically significant difference between the patients $(P>0.05)$. After the beginning of treatment, it was observed that the pain level in Group G patients regressed earlier and that it progressed at a significantly lower level (both in the first and third month controls).

Conclusion: It was concluded that addition of oral gabapentin to epidural corticosteroid application in patients with failed back surgery syndromes was effective in ameliorating pain at an early stage without significant side effects.

Keywords: failed back surgery syndrome, epidural corticosteroid, gabapentin

\section{Introduction}

Luschka was the first to describe degeneration and prolapse of the intervertebral disc in 1858. Later, in 1909, Krause and Oppenheim performed the first successful surgical excision of a herniated intervertebral disc. ${ }^{1}$ In 1934, Mixter and Barr demonstrated that a herniated disc could cause nerve root encroachment, ultimately producing back pain. The removal of the disc did not always result in pain relief. In 1951, Barr decided that a patient may have persistent low back pain, sciatica, or both, despite surgical intervention. $^{2}$ The evolved definition of failed back surgery syndrome (FBSS) is persistent or recurring low back pain, with or without sciatica following one or more lumbar operations. ${ }^{3}$ In the literature, the frequency of its occurrence is $1 \%-48 \%{ }^{4-9}$

Epidural fibrosis is among the most common causes of FBSS, and is often refractory to treatment. ${ }^{10}$ Repeated surgery for fibrosis has only a $30 \%-35 \%$ success rate, and 
$15 \%-20 \%$ of patients report worsening of their symptoms. ${ }^{10}$ The causes of epidural fibrosis include surgical manipulation of tissue at the time of surgery, bleeding, dural tears, and irritation from mechanical instability. ${ }^{10}$

Phospholipase A2, the rate-limiting enzyme in the conversion of arachidonic acid to prostaglandins and leukotrienes, has been found in high levels in discs removed at discectomy, ${ }^{11}$ and has been implicated as a primary inflammatory mediator and a cause for peripheral nerve injury. ${ }^{12}$ Corticosteroids are known to inhibit prostaglandin synthesis, impair both cellmediated and humoral immune responses, stabilize cellular membranes, and block nociceptive C-fiber conduction. ${ }^{13-18}$

Gabapentin is a structural analog of $\gamma$-aminobutyric acid and acts at the $\alpha_{2} \delta_{1}$ subunits of voltage-dependent calcium channels. It can act via primary afferent neurons, dorsal root ganglia, dorsal horn neurons, and supraspinal sites. ${ }^{19}$ Gabapentin was found to be effective in animal models of postoperative, inflammatory, and/or neuropathic pain. It has also been found in animal experiments that gabapentin decreases movement-associated responses in neuropathic pain and in peripheral inflammation. ${ }^{20}$

This study compared the analgesic efficacy of adding of oral gabapentin treatment to epidural corticosteroid application in patients with FBSS.

\section{Method}

This study was conducted at a university hospital, and the protocol was approved by the hospital's institutional review board. The participants in this study were recruited in a consecutive manner from referrals to one private practice affiliated with the hospital. Patients were eligible to participate in this study if they were older than 18 years, had primarily leg pain more than back pain, had been symptomatic for longer than six weeks, had undergone a lumbar spine magnetic resonance imaging (MRI) scan documenting a herniated nucleus pulposus estimated to have less than $50 \%$ (those whose herniated nucleus pulposus continued after operation were not included in the study and those whose operations took place at least three months earlier were included) intervertebral foraminal narrowing, or manifested clinical signs such as radicular pain and sensory or fixed motor deficits consistent with lumbar radiculopathy at the MRI-documented lumbosacral root level.

Patients were excluded from the study if they had a large herniated nucleus pulposus with severe central or foraminal stenosis on MRI, had segmental instability, had progressive neurologic deficits, had undergone prior epidural steroid injections, had a blood coagulation disorder, or had previously experienced an allergic reaction to local anesthetics or steroids. Patients who met the inclusion criteria signed an informed consent that described the trial with its risks, benefits, alternatives, and objectives as per the institutional review board protocol.

The patients (American Society of Anesthesiologists classification I-II, 42 cases, 23 females and 19 males, aged 25-73 years) were randomly assigned to two treatment groups, ie, Group K and Group G. Patients in each group were well informed about their disease, and the treatment modalities were applied. Furthermore, the patients in both groups were asked to keep a private pain diary during this research. Each patient was taught how to mark a visual analog scale (VAS) and the pain scale values at the given time intervals in the diary. Thereby, we had the chance to determine correctly when VAS values reached the value 4 (this is the value when the patients were relieved from pain and when the pain did not affect their regular sleep pattern). Consequently, this research is a prospective, randomized and nonblinded (but not placebo-controlled) research.

All injections were technically and successfully administered by the same anesthesiologist (BZ) at the epidural space as verified by epidurography. After sterile preparation, draping, and local anesthesia, epidural blocks were performed, typically at the L3/4 intervertebral space with a 20 -gauge $3.5 \mathrm{inch}(8.89 \mathrm{~cm})$ Touhy needle $\left(\mathrm{B}\right.$. Braun ${ }^{\mathrm{TM}}$ Melsungen, Germany) using the loss of resistance to air technique. Prior to each injection, $5 \mathrm{cc}$ of contrast medium $\left(\right.$ Omnipaque ${ }^{\circledR}$ ) was used to perform an epidurogram so that localization of the injection could be confirmed. All patients were treated prospectively with epidural injections consisting of $80 \mathrm{mg}$ methylprednisolone acetate in $10 \mathrm{~mL}$ of $0.125 \%$ bupivacaine. Lumbar epidural injection was performed in the lateral decubitus position. Within 30 minutes of the epidural block, all patients reported complete relief of back pain, with variable responses for lower extremity pain. At this time, there was no sensory anesthesia in the low back area and no motor or sensory anesthesia of the lower extremity.

Following epidural application of a single dose of methylprednisolone acetate in the Group K patients, an oral medical treatment containing naproxen sodium $(1100 \mathrm{mg} /$ day, once every 12 hours), tizanidine (12 mg/day, once every 12 hours), and vitamin $\mathrm{B}$ and $\mathrm{C}$ complex was devised and to be applied for one month. In Group G, oral gabapentin (1200 mg/day, three times a day, every eight hours) was added to the same treatment regime.

Pain levels of the informed patients were evaluated using VAS for straight leg raise to $45^{\circ}$ before, during, and after treatment, as well as in the first and third months. 
All data were collected in an Excel ${ }^{\circledR}$ sheet for documentation. For statistical analysis, the program SPSS 13.0 ${ }^{\circledR}$ for Windows (LEAD Technologies Inc., Charlotte, NC) was used. The Mann-Whitney U test was used to compare the statistical difference between the obtained demographic data (age, weight, and height). The Wilcoxon matched-pairs test was used to evaluate the statistical difference between VAS values, and the Chi-square test was used to determine the statistical difference between genders. In all cases, a $P$ value less than 0.05 was considered statistically significant.

\section{Results}

It was decided that there was not a significant difference between the average values of the demographic data $(P>0.05$, Table 1). It was identified before starting treatment that the VAS values of both groups were similar to each other $(P=0.142$, Table 2). In addition, it was seen that, compared with Group K cases (4.50 \pm 1.60 day), the pain level in Group $\mathrm{G}$ cases (for $3.45 \pm 1.70$ day) regressed earlier (the time when VAS was $<4$ ) after the treatment was started $(P=0.04)$. In parallel with this, it was observed during the first and third month controls that, compared with Group K, VAS values for Group G progressed at a significantly slower pace ( $P=0.003$ for the first month and $P=0.004$ for the third month, Table 3 ). During the sixth month when the research was completed, it was observed that the VAS values of Group $\mathrm{G}$ were significantly lower compared with Group K $(P<0.001$, Table 2$)$.

According to computerized tomography of the lumbar area and MRI examinations carried out in the first and third month controls, no epidural abscesses, hematoma, or osteoporotic changes were observed. On the other hand, no side effects, except for slight sedation due to oral gabapentin use, were observed in Group G patients.

\section{Discussion}

Many discectomy procedures for disc herniation are performed each year. The removal of the disc does not always result in pain relief. Discectomy may eliminate the mechanical reasons for pain, but a painful inflammatory condition may continue in the postoperative period, and the inflammation triggered by the surgical procedure can even start the process

Table I Demographic information of the patients

\begin{tabular}{lllll}
\hline & Age (years) & Sex (M/F) & Weight (kg) & Tall (cm) \\
\hline Group K & $42.10 \pm 12.75$ & $9 / 12$ & $72.55 \pm 14.98$ & $164.10 \pm 14.59$ \\
Group G & $47.60 \pm 14.61$ & $10 / 11$ & $68.15 \pm 12.67$ & $158.80 \pm 13.45$ \\
$P$ & 0.183 & $>0.05$ & 0.369 & 0.327 \\
\hline
\end{tabular}

Table 2 Comparison of the patients' visual analog score values (mean \pm standard deviation) before and after treatment (with straight leg raising test, $45^{\circ}$ angle)

\begin{tabular}{lllll}
\hline & & Group K & Group G & P \\
\hline VAS & Pretreatment & $7.70 \pm 0.47$ & $8.05 \pm 0.69$ & 0.142 \\
& $\begin{array}{l}\text { End of treatment } \\
\text { (six months later) }\end{array}$ & $5.60 \pm 0.60$ & $2.20 \pm 1.28$ & $<0.001$ \\
$P$ & $<0.05$ & $<0.001$ & \\
\hline
\end{tabular}

of fibrosis and cause pain later on. Reported failure rates for this surgery range from $2 \%$ to $20 \%{ }^{21}$ Patients with low back pain in whom discectomy fails to improve pain have been categorized in the surgical literature as FBSS. The reported frequency of FBSS may range from $1 \%$ to $48 \% .^{4-9}$

Definitions for FBSS are difficult to find and appear to differ. Wynn Parry has defined FBSS as intractable back pain and sciatica in patients who have failed to improve despite numerous courses of treatment, including physiotherapy and surgery. ${ }^{22}$ Fan and Chong have defined FBSS as pain and functional incapacitation of varying degrees in patients following spinal surgery for low back pain..$^{23}$ Long did not define it, but pointed out that it was an imprecise term used to categorize a heterogeneous group of patients who share only residual symptoms after treatment failure. ${ }^{24}$ The lack of a universally accepted definition for FBSS has made research into this syndrome difficult. However, it is clear that central to a definition of FBSS are two notions, ie, patients with this syndrome have chronic low back pain, and these chronic pain patients have had one or more surgeries on their backs which have not helped their low back pain. ${ }^{25}$

Epidural fibrosis is among the most common causes of FBSS, and it is often refractory to treatment. The pathophysiology of epidural fibrosis is relatively well understood. Fibroblasts from damaged erector spinae muscles overlying the surgery site follow the extension of the postoperative hematoma into the vertebral canal. Causes of epidural fibrosis include the surgeon's manipulation of tissue at the time of surgery, bleeding, dural tears, and irritation from mechanical instability. ${ }^{19}$

There are some experiments going on in animals concerning, eg, the efficacy of pimecrolimus or amniotic

Table 3 Comparison of the patients' visual analog score values in the first and third months (with straight leg raising test, $45^{\circ}$ angle)

\begin{tabular}{lllll}
\hline & & Group K & Group G & $P$ \\
\hline VAS & One month later & $1.70 \pm 0.47$ & $0.90 \pm 0.92$ & 0.003 \\
& Three months later & $2.15 \pm 0.37$ & $1.50 \pm 0.76$ & 0.004 \\
\hline
\end{tabular}


membrane in alleviating or preventing epidural adhesions that occur following laminectomy. ${ }^{26,27}$ On the other hand, many biologic (such as fibrin glue) and nonbiologic materials (such as methylprednisolone acetate) have been tried in a quest to prevent epidural fibrosis. ${ }^{28}$ Spinal endoscopic adhesiolysis may be used as an effective treatment modality for chronic refractory low back pain and radiculopathy that is related to epidural adhesions. ${ }^{29}$ Moreover, there is a pilot study which shows that the use of a Vaseline ${ }^{\circledR}$-sterile oil-morphine compound is effective in preventing postoperative pain and postoperative adhesion after lumbar microdiscectomy. ${ }^{30}$ However, inducing the least amount of injury to the anatomy of the tissues and very good hemostasis seem to be the most effective methods in the prevention of epidural fibrosis. ${ }^{28}$

Epidural steroid injections are an accepted treatment for low back pain with a radicular component secondary to lumbar disc pathology or spinal stenosis. ${ }^{31}$ Traditional epidural injection routes are dorsal, and corticosteroid spread to the ventral target site occurs by diffusion. Additionally, the dorsal median epidural septum may confine the spread of dorsal epidural flow to the side ipsilateral to the injection. ${ }^{32}$ The mechanism of therapeutic benefit is attributed to relieving the inflammation secondary to mechanical and/or chemical nerve root irritation. ${ }^{31}$

Epidural steroid application in patients who receive anticoagulant treatments or who have local anesthetic allergies, skin infections, central nerve system disorders, diabetes, intestinal and bladder disorders, congestive cardiac failure, or exogenous steroid application restrictions is contraindicated. ${ }^{33}$ Other complications connected with dural penetration, such as headache, nausea, vomiting, steroid myopathy, arachnoiditis, meningitis, water-salt retention, and vision loss, have also been reported. ${ }^{34}$ Fluoroscopic guidance and contrast confirmation allows confident placement of the steroid within the epidural space, avoiding inadvertent intrathecal or intravascular injection. We use a stationary $\mathrm{C}$-arm fluoroscope and believe that the interlaminar lumbar approach requires the ability to image in both frontal and lateral planes. On the other hand, Fredman et al reported that the resistance loss technique is a safe indicator in determining the lumbar epidural intervals in patients with FBSS, ${ }^{35}$ and we have also applied this technique successfully in all our patients.

Surgical injury results in acute nociception, as well as sensitization of the dorsal horn of the spinal cord, which can lead to hyperalgesia and allodynia. ${ }^{36}$ During laminectomy and discectomy, there is trauma to the soft tissues and bony structures, which can result in severe pain at rest as well as during movement. There may be an additional component of neuropathic pain due to nerve root compression. Even though gabapentin has no antinociceptive effects, it has been shown in animal experiments that it has both antiallodynic and antihyperalgesic effects. ${ }^{37}$ The anticonvulsant gabapentin has an affinity to voltage-dependent calcium channels and amino acid transfer, and modulates the release of excitatory amino acids at the level of the dorsal horn of the spinal cord. It reduces dorsal horn responses to fiber input and blocks ectopic discharges from injured nerves. ${ }^{38,39}$ Gabapentin was initially reported to be effective in treating different types of neuropathic pain. ${ }^{40}$ Rosenberg et al also performed a retrospective study of gabapentin for use in neuropathic pain and low back pain. ${ }^{41}$ The fact that we have shown a similar result to that of Braverman et $\mathrm{al}^{10}$ in our patients, who were radiologically proven to have epidural fibrosis, indicates that gabapentin might be an effective alternative treatment for FBSS.

On the other hand, the psychosocial status of cases is regarded as a risk factor for development of $\mathrm{FBSS}^{25}$ In our study, we did not have the opportunity to investigate psychosocial status in our patients, and this may limit the results we obtained. However, addition of gabapentin to epidural corticosteroid application achieved a significant reduction in pain scores.

\section{Conclusion}

FBSS, most commonly caused by epidural fibrosis, represents an extremely difficult clinical problem, made more complex by the multidimensional nature of pain itself. Epidural corticosteroids, because of their anti-inflammatory properties, have been the cornerstone of treatment. The mainstay of management of recalcitrant symptomatic epidural fibrosis at this time is pharmacologic intervention. In our research, we identified that addition of gabapentin to epidural corticosteroid application is helpful in reducing pain in FBSS.

\section{Disclosure}

The author declares no competing interests in this work.

\section{References}

1. Ivanic GM, Pink TP, Homann NC, Scheitza W, Goyal S. The postdiscectomy syndrome - aetiology, diagnosis, treatment, prevention. Arch Orthop Trauma Surg. 2001;121:494-500.

2. Anderson SR. A rationale for the treatment algorithm of failed back surgery syndrome. Curr Rev Pain. 2000;4:395-406.

3. North RB, Campbell JN, James CS, et al. Failed back surgery syndrome: 5 year follow-up in 102 patients undergoing repeated operation. Neurosurgery. 1991;28:685-690.

4. Frymoyer JW, Hanley E, Howe J, Kuhlmann D, Matteri R. Disc excision and spine fusion in the management of lumbar disc excision. A minimum ten-year follow-up. Spine. 1978;3:1-6. 
5. Herron LD, Pheasant HC. Bilateral laminotomy and discectomy for segmental lumbar disc disease: Decompression with stability. Spine. 1983;8:86-97.

6. Howorth B. Low backache and sciatica: Results of surgical treatment. Part II. Removal of nucleus pulposus and spine fusion. J Bone Joint Surg. 1964;46:1500-1509.

7. Kallio E, Torma T. Late follow-up of lumbar disc surgery without fusion. J Int Coll Surg. 1965;44:191-199.

8. Salenius P, Laurent LE. Results of operative treatment of lumbar disc herniation. A survey of 886 patients. Acta Orthop Scand. 1977; 48:630-634.

9. Spangfort EV. The lumbar disc herniation: A computer aided analysis of 2504 operations. Acta Orthop Scand. 1972;142 Suppl:1-95.

10. Braverman DL, Slipman CW, Lenrow DA. Using gabapentin to treat failed back surgery syndrome caused by epidural fibrosis: A report of 2 cases. Arch Phys Med Rehabil. 2001;82:691-693.

11. Saal JS, Franson RC, Dobrow R, Saal JA, White AH, Goldthwaite N. High levels of inflammatory phospholipase A2 activity in lumbar disc herniations. Spine. 1990;15:674-678.

12. Chen C, Cavanaugh JM, Ozaktay AC, Kallakuri S, King A. Effects of phospholipase A2 on lumbar nerve root structure and function. Spine. 1997;22:1057-1064.

13. Claman HN. Corticosteroid and lymphoid cells. N Engl J Med. 1972; 287:388-397.

14. Dilke TF, Burry HC, Grahame R. Extradural corticosteroid injection in the management of lumbar nerve root compression. BMJ. 1973; 2:635-637.

15. Johansson A, Hao J, Sjolund B. Local corticosteroid application blocks transmission in normal nocioceptive C-fibers. Acta Anesthesiol Scand. 1990;34:335-338.

16. Kantrowitz F, Robinson DR, McGuire MB, Levine L. Corticosteroids inhibit prostaglandin production by rheumatoid synovia. Nature. 1975 ; 258:737-739.

17. Lee HM, Weinstein JN, Meller ST, Hayashi N, Spratt KF, Gebhart GF. The role of steroids and their effects on phospholipase A2: An animal model of radiculopathy. Spine. 1998;23:1191-1196.

18. Rinehart JJ, Balcerzak SP, Sagone AL, LoBuglio AF. Effects of corticosteroids on human monocyte production. J Clin Invest. 1974;56: 1337-1343.

19. Gutton KG, Martin DJ, Pinnock RD. Gabapentin inhibits high threshold calcium channel currents in cultured rat dorsal root ganglion. $\mathrm{Br} J$ Pharmacol. 2002;135:257-265.

20. Patel S, Naeem S, Kesingland A, et al. The effects of GABA(B) agonists and gabapentin on mechanical hyperalgesia in models of neuropathic pain inflammatory pain in the rat. Pain. 2001;90:217-226.

21. Goupille P. Causes of failed back surgery syndrome. Rev Rhum. 1996; 63:235-239.

22. Wynn Parry CB, Girgis F, Moffat B, Bhalla AK. The failed back: A review. J R Soc Med. 1988;81:348-351.

23. Fan YF, Chong VFH. MRI findings in failed back surgery syndrome. Med J Malaysia.1995;50:76-80.

24. Long DM. Failed back surgery syndrome. Neurosurg Clin North Am. 1991;2:899-917.
25. Fishbain DA, Cutler RB, Rosomoff HL, Rosomoff RS. Pain facility treatment outcome for failed back surgery syndrome. Curr Rev Pain. 1999;3:10-17.

26. Cemil B, Tun K, Kaptanoglu E, et al. Use of pimecrolimus to prevent epidural fibrosis in a postlaminectomy rat model. J Neurosurg Spine. 2009;11:758-763.

27. Tao H, Fan H. Implantation of amniotic membrane to reduce postlaminectomy epidural adhesions. Eur Spine J. 2009;18: 1202-1212.

28. Cekinmez M, Sen O, Atalay B, et al. Effects of methyl prednisolone acetate, fibrin glue and combination of methyl prednisolone acetate and fibrin glue in prevention of epidural fibrosis in a rat model. Neurol Res. 2010;32:700-705.

29. Hayek SM, Helm S, Benyamin RM, Singh V, Bryce DA, Smith HS Effectiveness of spinal endoscopic adhesiolysis in post lumbar surgery syndrome: A systematic review. Pain Physician. 2009;12:419-435.

30. Mastronardi L, Pappagallo M, Tatta C, Roperto R, Elsawaf A, Ferrante L. Prevention of postoperative pain and of epidural fibrosis after lumbar microdiscectomy: Pilot study in a series of forty cases treated with epidural vaseline-sterile-oil-morphine compound. Spine (Phila Pa 1976). 2008;33:1562-1566.

31. O’Neill C, Derby R, Knederes L. Precision injection techniques for the diagnosis and treatment of lumbar disc disease. Semin Spine Surg. 1999;11:104-118.

32. Furman MB, O’Brien EM, Zgleszewski TM. Incidence of intravascular penetration in transforaminal lumbosacral epidural steroid injections. Spine. 2000;25:2628-2632.

33. Weinstein SM, Herring SA, Derby R. Contemporary concepts in spine care: Epidural steroid injections. Spine. 1995;16:1842-1846.

34. Young WF. Transient blindness after lumbar epidural steroid injection Spine. 2002;27:476-477.

35. Fredman B, Nun MB, Zohar E, et al. Epidural steroids for treating "failed back surgery syndrome": Is fluoroscopy really necessary? Anesth Analg. 1999;88:367-372.

36. Dirks J, Moiniche S, Hilsted KL, Dahl JB. Mechanisms of postoperative pain. Clinical indications for a contribution of central neuronal sensitization. Anesthesiology. 2002;97:1591-1596.

37. Field MJ, Holloman EF, McCleary S, Hughes J, Singh L. Evaluation of gabapentin and S-(+)-3-isobutyl GABA in a rat model of postoperative pain. J Pharmacol Exp Ther. 1997;282:1242-1246.

38. Gee NS, Brown JP, Dissanayake VU, Offord J, Thurlow R, Woodruff GN. The novel anticonvulsant drug, gabapentin, binds to the alpha 2-delta subunit of a calcium channel. J Biol Chem. 1996;271:5768-5776.

39. Mathews EA, Dikenson AH. Combination of gabapentin and morphine mediates enhanced inhibitory effects on dorsal horn neuronal responses in rat model of neuropathy. Anesthesiology. 2002;96:633-640.

40. Rosner H, Rubin L, Kestenbaum A. Gabapentin adjunctive therapy in neuropathic pain states. Clin J Pain. 1996;12:56-58.

41. Rosenberg JM, Harrell C, Ristic H, Werner RA, de Rosayro AM. The effect of gabapentin on neuropathic pain. Clin J Pain. 1997;13: $251-255$.
Clinical Pharmacology: Advances and Applications

\section{Publish your work in this journal}

Clinical Pharmacology: Advances and Applications is an international, peer-reviewed, open access journal publishing original research, reports, reviews and commentaries on all areas of drug experience in humans. The manuscript management system is completely online and includes a very quick and fair peer-review system, which is all easy to use.

\section{Dovepress}

Visit http://www.dovepress.com/testimonials.php to read real quotes from published authors. 